\title{
Erratum: Cognitive neuroscience: new kids on the block?
}

Clayton Curtis \& Lila Davachi

Nat. Neurosci. 11, 621 (2008); published online 27 May 2008; corrected after print 17 June 2008

In the version of this article initially published, the authors Michael L. Platt and Marty Woldorff were not listed as authors of the book Principles of Cognitive Neuroscience. The error has been corrected in the PDF version of the article.

Corrigendum: Spiking and nonspiking classes of oligodendrocyte precursor glia in CNS white matter

\author{
Ragnhildur Káradóttir, Nicola B Hamilton, Yamina Bakiri \& David Attwell \\ Nat. Neurosci. 11, 450-456 (2008); published online 2 March 2008; corrected after print 21 May 2008
}

In the version of this article initially published, the units for the values reported for resistance in Figure $2 \mathrm{i}, \mathrm{j}$ were incorrect. The correct unit should be gigaohms. In addition, the authors did not state that the cell death experiments in Figure $6 \mathrm{e}, \mathrm{f}$ were carried out using a physiological extracellular magnesium concentration of $1 \mathrm{mM}$. This error has been corrected in the HTML and PDF versions of the article.

\section{Corrigendum: Decision-making with multiple alternatives}

Anne K Churchland, Roozbeh Kiani \& Michael N Shadlen

Nat. Neurosci. 11, 693-702 (2008); published online 18 May 2008; corrected after print 17 June 2008

In the version of this article initially published, the panels in Figure 1 were mislabeled. The correct legend should be 'Psychometric functions for the 29 experiments that included the $90^{\circ}$ control are shown in e. Chronometric functions are shown in f'. This error has been corrected in the HTML and PDF versions of the article. 